\title{
Evaluation of Potential Cashew Clones for Utilization in Ghana
}

\author{
Abu Mustapha Dadzie', Paul Kwesi Krah Adu-Gyamfi' ${ }^{1}$, Stephen Yaw Opoku', \\ Julius Yeboah1, Abraham Akpertey', Kwabena Opoku-Ameyaw', Michael Assuah"1, \\ Esther Gyedu-Akoto', Wiseborn Bismark Danquah ${ }^{2}$ \\ ${ }^{1}$ Cocoa Research Institute of Ghana (CRIG), Tafo-Akim, Ghana \\ ${ }^{2}$ Department of Plant Pathology University of California, Davis, USA \\ Email: xmusto@yahoo.co.uk
}

Received 22 April 2014; revised 24 May 2014; accepted 1 June 2014

Copyright @ 2014 by authors and Scientific Research Publishing Inc.

This work is licensed under the Creative Commons Attribution International License (CC BY).

http://creativecommons.org/licenses/by/4.0/

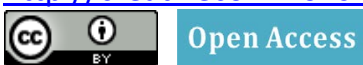

\begin{abstract}
Cashew (Anacardium occidentale $\mathrm{L}$ ) is an important cash crop cultivated by about 3 million households in Africa and serves as the livelihood for many African farmers, especially Ghana. Despite the importance of cashew as a commodity crop with increasing cultivation in Northern Ghana, the crop is challenged with problems such as, low and variable nut yields, low kernel out turn percentage and susceptibility to insect pests as a result of establishing cashew farms with unselected seeds. In order to address the challenges, the Cocoa Research Institute of Ghana established a clonal evaluation trial in Northern Ghana (dry savanna vegetation) to indentify promising clones for subsequent distribution to cashew farmers as an interim measure. The trials consisted of ten different clones planted in Randomised Completed Block Design (RCBD) with four replicates. Parameters evaluated were yield, yield efficiency, nut weight, percentage out turn and canopy area. Data analysis was performed with Gen Stat version 11.0 and the results revealed significant differences $(P<0.05)$ in the performance of the clones in all the parameters considered. Such differences allowed the identification of promising clones over other clones tested. A few clones combined two or three traits (parameters) which were significantly different from the rest of the clones evaluated. No single clone was found to be significantly different from the rest in terms of all the parameters considered. However a greater proportion of the clones were found to produce yields far above average yields recorded by unselected cashew trees in farmers' fields. Clones W266 and W278 seem outstanding for most of the parameters considered, though not exclusive.
\end{abstract}

\section{Keywords}

Cashew, Clone, Yield, Kernel and Efficiency 


\section{Introduction}

Cashew (Anacardium occidentale L.) is a tropical nut crop of the family Anacardiaceae, and consists of 75 genera and 700 species [1]. It has become one of the most important export crops produced in a number of regions and countries of the tropics, including Ghana and some East African countries, especially Tanzania. It is estimated that about 3 million households in Africa are involved in cashew production with an average of 3 hectares of farm land [2]. Cashew, therefore, contributes significantly to the economy and livelihood of the smallholder farmers in Africa. In Ghana, the annual export of raw cashew nut in 2009 was 70,000 tons contributing approximately US \$ 40 million in foreign exchange earnings [3].

Despite the importance of cashew as a commodity crop with increasing cultivation in Ghana, the crop is challenged with problems such as, low and variable nut yields, low kernel out turn percentage and susceptibility to insect pests and diseases [4] [5]. In Northern Ghana, yield per tree in farmers' fields are generally low and highly varied with some trees not producing anything whilst the best usually produce between 2 - $3 \mathrm{~kg}$ of nuts per tree [6]. The huge degree of yield variation is usually attributed to genotypic and environmental differences [7] [8]. Studies by the Cocoa Research Institute of Ghana (CRIG) and the Cashew Development Unit of the Ministry of Food and Agriculture in Ghana indicated that 50\% of the highest yielding trees in farmers' field produce at least $70 \%$ of the plot yield, while the remaining $30 \%$ of the yields are produced by $50 \%$ lowest yielding trees. This finding is due to the fact that most cashew farms were established from unselected cashew seeds introduced into the country in the 1960s as part of the governments' strategies to alleviate poverty in the rural areas and to widen the base of the agricultural exports [9].

The initiative though important, led to the introduction of trees with high heterogeneity and yield variability in Northern Ghana [4]. To address the problems of low yields and yield variability among cashew trees in farmers' field within the earliest possible time, the Cocoa Research Institute of Ghana assembled a wide range of cashew germplasm materials from cashew seeds within Ghana (local collections) and other countries including Benin, Tanzania, Brazil and Mozambique at Wenchi and Bole, Agricultural Research Stations for evaluation [10]. A ten year yield data obtained from over two hundred local accessions evaluated at Wenchi in the transitional belt of Guinea-Savanna vegetation (data not presented) provided insight for the selection of ten top yielding trees which met a set criteria such as anthracnose resistance, early flowering and bearing for further evaluation to identify and supply scions from the most promising genotypes in the dry Savanna vegetation to farmers within Northern Ghana as an interim measure to address the problem of low yields and yield variability.

This paper presents the findings of a study, aimed at evaluating the potential yield of ten different clones, their percentage out turn, yield efficiency and tree architecture (canopy area) under marginal condition, especially in Northern Ghana where cashew cultivation is a major business.

\section{Materials and Methods}

A clonal evaluation experiment was carried out in June 2005-2013 at the Cocoa Research Institute of Ghana substation at Bole $\left(9^{\circ} 01^{\prime} \mathrm{N}, 2^{\circ} 29^{\prime} \mathrm{W}, 309\right.$ masl) in the Guinea Savannah zone of northern Ghana. The mean annual rainfall and daily temperature of the site are $1087 \mathrm{~mm}$ and $26.1^{\circ} \mathrm{C}$, respectively [11]. The soils of the station are mainly Ferric Luvisol with smaller areas of Eutric Regosols and Lithosols [12].

Ten cashew clones were used in this study. The clone selection was based on the results of analysis of yield for a period of ten years at Wenchi Agriculture station in the Brong-Ahafo region of Ghana. The clones were W044, W079, W151, W131, W266, W268, W273, W278 and W227. Clone W079 was used as a control clone in this experiment because it is known to be a high yielding genotype in the germplasm collection. All the ten clones were raised vegetatively by tip grafting and were transplanted to the field in June, 2005. The design was randomized block, with four replicates, at a spacing of $10 \mathrm{~m}$ between rows and $10 \mathrm{~m}$ within rows. The plot size was 10 trees per plot which were pruned when necessary. The yields were record on individual tree basis from 2009 to 2013 commencing from the first week of October to January and sometimes up to February the following year. Recording of individual tree yield was done daily from October to December each year from 2009 to 2013. However the data collected from 2009 was not used in the analysis because nuts produced was very few and scanty with few trees yielding a hand full of nuts whilst others did not produce any nuts at all.

Weighing of fresh nuts was carried out in the field using a weighing balance Salter Brecknell 235-6S-110 mechanical scale balance (Brecknell, USA).

A $1 \mathrm{~kg}$ sample of randomly collected nuts from each plot was used for nut analysis. Following protocols de- 
scribed by [13]-[15]. The mean nut weight was calculated by dividing sample weight by number of nuts in the sample. Kernel weight was calculated using formula $\mathrm{KWt}=(\mathrm{WtGK}) /(\mathrm{NGK})$, where $\mathrm{KWt}=$ Kernel weight, WtGK = weight of good kernels and NGK = number of good kernels. Equally, percentage kernel out turn was calculated using formula OT\% $=(\mathrm{KWt} / \mathrm{NtWt}) \times 100$ where OT\% $=$ percentage kernel out turn, $\mathrm{KWt}=$ kernel weight and NtWt = nut weight. Nut and kernel weights were recorded in each year and the mean was used in the analysis of the data. Canopy area was estimated by computing the average of the radius of the canopy measuring from (North-South direction and East-West direction) in the formula $\pi r^{2}$ where, $\pi=3.142$ and $r=$ radius of canopy. Yield efficiency was estimated by the ratio of average yield over the average stem diameter.

\subsection{Data Analysis}

The data generated were analysed using GenStat Release 11.0 for Windows (VSN International). Data for the replicate experiments were combined in a single analysis because no significant interactions were found between the different experiments. The data were checked for homogeneity of variance and normality of residuals. All data were analysed by parametric interaction analysis of variance (ANOVA) and the differences between treatment means detected using least significant difference.

The analysis of variance was carried out on yield, nut quality (out turn) and canopy circumference using Gen stat statistical analysis package version 11.0. The means were separated using using lsd.

\section{Results}

\subsection{Yield Performance of Ten Cashew Clones}

Statistical analysis of the yields of the ten clones over the period under study indicates significant differences in yields among the clones tested $(P<0.05)$ for all harvest years except for 2010 results where no differences were found in the clone yield. This observation was expected as this was the early yields and as a result some trees produced only few nuts whilst others produced no nuts at all. The analysis also revealed a high percentage coefficient of variation (\% CV) due to the random and scanty yields recorded by some trees at the time of harvest.

In the subsequent years (2011, 2012 and 2013) where significant differences were observed in the yields of the clones, it was also observed that percentage coefficient of variation (\% CV) also gradually decreased over the four year period as most trees produced appreciable yields (Table 1). A similar observation was reported by Masawe [16] during an evaluation of five hybrid families in South East of Tanzania. Higher (\% CVs) in cashew yields have previously been reported by Eijnatten and Abubaker [17], Nair and Prabhakaran [18], Neto [19], Mead and Martin [20]. Observation of the yield performance often showed that, (W266 and W278) were consistently high compared to the control clone, W079 (Table 1). Considering the yields of the clones for the year 2013, it could be estimated that clones W268, W151, W044, W266, W278, have the potential of producing yields of 982, 1015, 1120, 1351 and $1443 \mathrm{~kg} / \mathrm{ha} /$ year respectively, at a density of $10 \mathrm{~m} \times 10 \mathrm{~m}$. These yields are comparable to average yields reported in Vietnam [21] and the world's average cashew yields which ranges between 0.5 - 1 ton [22]. From the results (Table 1), it can be seen that although, yields of most clones continue to rise from year to year; these trees have yet to produce the yields of 17 - $24 \mathrm{~kg} /$ tree/year reported by Masawe [23] from some hybrid trees, six years after planting in the field. Despite the general ascending trend observed here (Table 1), it could also be noticed that some clones such as W268 tend to exhibit the alternate bearing phenomenon common to most tree crops.

\subsection{Yield Efficiency Estimation}

Yield efficiency was estimated as the average yield in kilograms dry cashew nut per tree from the commencement of bearing divided by the stem cross-sectional area in $\mathrm{m}^{2}$. Statistical analysis of the yield efficiency indicates significant differences among the clones $(P<0.05)$. In Table 2 , it could be seen that the yield efficiency increased as the nut yield increased over the years. A few clones such as W110, W266, W268 and W151 which showed consistent high efficiencies over the years, begun to decline in yr 2013 except clone W268. This might probably be due to sudden increase in the plant girth whiles yield did not appreciate exponentially. Yield efficiency provides insight on the ratio of nut yield to the trunk cross sectional area. High values indicate high performance. 
Table 1. Mean yield of cashew clones from year 2010 to 2013.

\begin{tabular}{ccccc}
\hline Genotypes & \multicolumn{2}{c}{ Mean yield (kg/tree/yr) } & Yr 2012 & Yr 2013 \\
\hline W044 & Yr 2010 & Yr 2011 & 8.34 & 11.2 \\
W079 & 0.70 & 3.13 & 4.36 & 8.29 \\
W227 & 0.33 & 1.66 & 3.07 & 7.41 \\
W273 & 0.18 & 2.86 & 2.97 & 7.88 \\
W278 & 0.39 & 4.98 & 7.28 & 14.43 \\
W131 & 0.49 & 4.12 & 4.06 & 6.33 \\
W110 & 0.21 & 1.72 & 2.66 & 6.66 \\
W268 & 0.38 & 4.64 & 8.12 & 9.82 \\
W266 & 0.32 & 10.11 & 11.34 & 13.51 \\
W151 & 0.77 & 8.26 & 5.82 & 10.15 \\
\hline LSD (P 0.05) & 1.04 & 3.01 & $5.4^{* *}$ & 31.7 \\
CV (\%) & ns & 6.8 & $3.8^{* *}$ \\
\hline
\end{tabular}

LSD = Least Significant Difference, CV $=$ Coefficient of Variation; * Significant at $P<0.05$, ** = highly significant at $P<0.01$, and ns $=$ Not significant at $P<0.05$.

Table 2. Mean yield efficiency of cashew clones from year (2010-2013).

\begin{tabular}{ccccc}
\hline & & \multicolumn{2}{c}{ Yield Efficiency/tree/year $\left(\mathrm{Kg} / \mathrm{m}^{2}\right)$} \\
\hline Genotype & 2010 & 2011 & 2012 & 2013 \\
W044 & 11.88 & 60.07 & 96.79 & 20.81 \\
W079 & 4.73 & 31.11 & 62.14 & 30.89 \\
W227 & 2.27 & 21.39 & 66.81 & 34.52 \\
W273 & 6.67 & 15.92 & 83.81 & 78.33 \\
W278 & 9.73 & 34.86 & 90.66 & 44.31 \\
W131 & 1.25 & 41.47 & 97.94 & 27.14 \\
W110 & 10.66 & 28.79 & 116.38 & 112.63 \\
W268 & 10.31 & 43.21 & 61.77 & 150.78 \\
W266 & 13.22 & 54.18 & 103.11 & 81.68 \\
W151 & 26.41 & 33.27 & 95.94 & 62.54 \\
LSD (P<0.05) & $14.03^{* *}$ & $43.41^{*}$ & $\mathrm{~ns}$ \\
CV (\%) & 35.60 & 30.67 & 28.11 & $94.14^{*}$ \\
\hline
\end{tabular}

LSD = Least Significant Difference, CV $=$ Coefficient of Variation; * = Significant at $P<0.05$, ** = highly significant at $P<0.01$.

\subsection{Nut Weight}

Nut weight amongst other yield component is a very essential component paramount to cashew farmers, consumers, as well as cashew breeders in selection programmes. Analysis performed on the weight of nuts showed significant differences in the nut weight at $(P<0.05)$. Generally, clone W227 recorded the highest nut weight of $8.6 \mathrm{~g}$ whilst W151 recorded the least of $4.9 \mathrm{~g}$. Mean nut weight of the trial was $6.3 \mathrm{~g}$, indicating that $60 \%$ of the clones were below the trial mean (Figure 1). Though a greater proportion were below the trial mean, the magnitude of the trial mean gives a good indication that there are some exceptional clones with high nut weight which has the tendency to raise the kernel export grade to the acceptable range of 180 - 450 White Whole (WW) kernel per pound. Nonetheless, the mean weight recorded by W227 seems comparable to record weights reported elsewhere. According to [23] the best performing cashew hybrid (AC4 x AZA17) in a trial in Tanzania recorded an average nut weight of (8.33 g). This pre-suggests that the heavy nut trait exhibited by W227 could be exploited in the breeding programme of Ghana for the development of improved cashew hybrids in Ghana.

\subsection{Percentage Out Turn Estimation}

Analysis of variance of percentage out turn showed significant differences among the clones evaluated at $(P<$ 


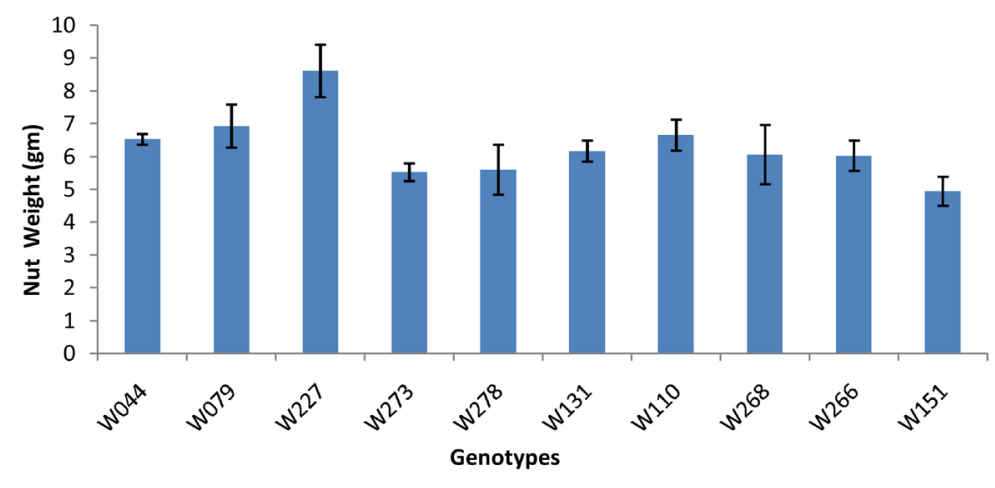

Figure 1. Average nut weight of ten clones from 2010 to 2013. Bars represents standard error of difference.

0.05). This ranged from as low as $22.0 \%$ (W266) to $37.7 \%$ (W278) (Figure 2). The observed differences could be exploited for further breeding work. Again, the results obtained shows that most of the clones approached 30 percent out turn, except for clone (W266) which produced a low percentage out turn. Generally, the overall performance of the entire clones is very much comparable to percentage out turns reported elsewhere [23]. Clone (W278) which produced the highest percentage could be used as a potential breeding parent to improve upon percentage out turn of some high yielding clones with low percentage out turn through hybridization programme.

\subsection{Canopy Area}

Statistical analysis performed on the average canopy spread shows significant differences between the canopy area of the genotypes at $(P<0.05)$. Canopy area varied from $3.8 \mathrm{~m}^{2}$ to $5.9 \mathrm{~m}^{2}$. Genotype W227 recorded the largest canopy area whilst W273 recorded the smallest. Genotype with large canopy area may require large plant spacing compared to genotypes with low or medium canopy area such as exhibited by W273 (Figure 3). Cashew produces flowers at the peripheries of the canopy and as such, early canopy merger affects cashew yields, therefore, genotypes with large canopy area may require larger plant spacing. The mean canopy area of the population was $5.0 \mathrm{~m}^{2}$, this suggests that $50 \%$ of the population have larger canopy area whilst the remaining $50 \%$ have lower canopy area compared to the population mean.

A further statistical test was performed to assess the correlation between average cumulative canopy area and average cumulative yield at $(P=0.05)$. The result indicated no significant correlation between the yield and the canopy area, though a weak positive correlation $(P>0.05 ; \mathrm{r}=0.0126)$ was observed (Figure 4$)$.

\section{Discussion}

Yield is one of the most important parameters considered in almost every crop improvement programme. Analysis of the yield over the course of this study revealed significant differences between the genotypes tested with the exception of 2010 where yields were generally low and scanty. The high mean yield observed for the study is an indication that there are potentially high yielding clones among the evaluated clones in Ghana. These clones have yields comparable to high yields reported in Vietnam [21] and other parts of the world [22]. Nut yield of $105 \mathrm{~kg} /$ tree/year for some cashew hybrids (AC4 x AC6) in Tanzania has been reported [23] as probably the record high yield of all time in the world. Such extraordinary yield might probably be as a result of heterosis emanating from two superior parents. Samal [24] also reported that cashew yields in India ranges from 0-48 $\mathrm{kg} /$ tree/year. Further report on cashew yields suggests that, high yielding genotypes in Thailand produce yields around $13.7 \mathrm{~kg} /$ tree/year seven years after planting [25]. This observation is comparable to the yields recorded by clones W044, W278 and W266 in this study which produced yields of 11.2, 13.51 and $14.43 \mathrm{~kg} /$ tree/year, respectively during the year 2013 (eight years after planting in the field). These clones have consistently produced incremental yields over the period of observation whilst some other clones such as W268, W273 and W110 displayed the alternate bearing phenomenon common to crops like Kola (Cola nitida). The trend of bearing displayed by these clones means that nut yield may not be easily predicted with certainty. 


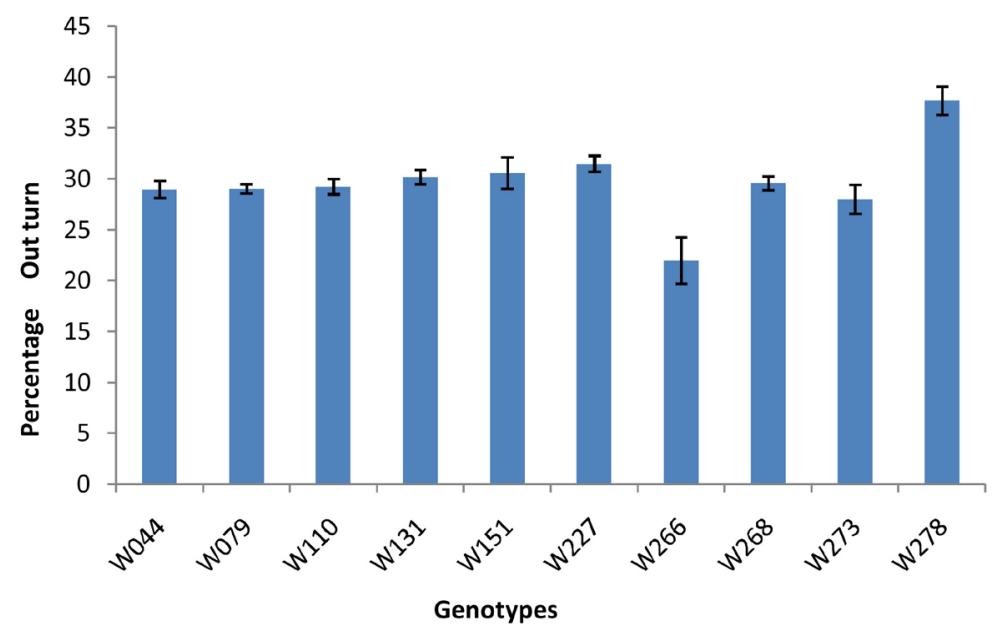

Figure 2. Average percentage out turn of ten clones from yr 2010 to yr 2013 Bars represents standard error of difference.

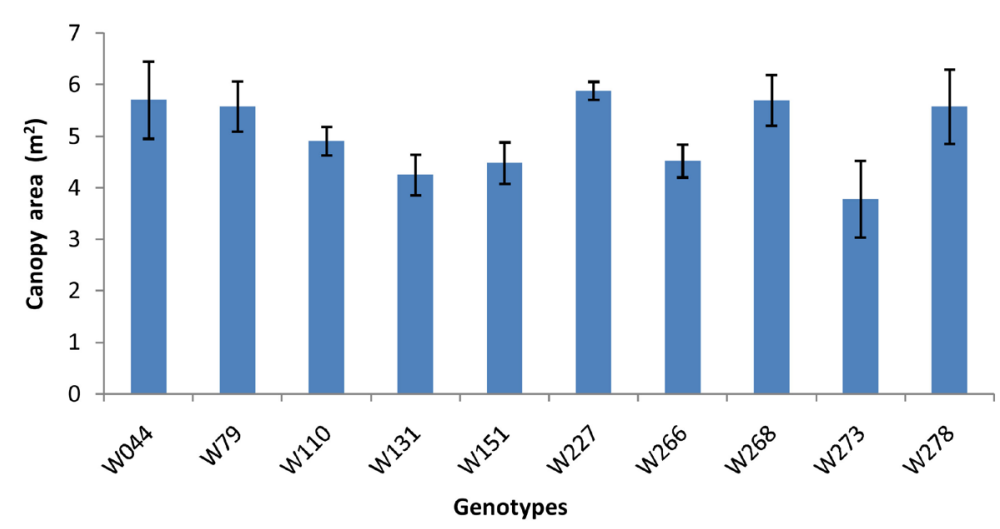

Figure 3. Average canopy area of ten clones from 2010 to 2013. Bars represents standard error of difference.

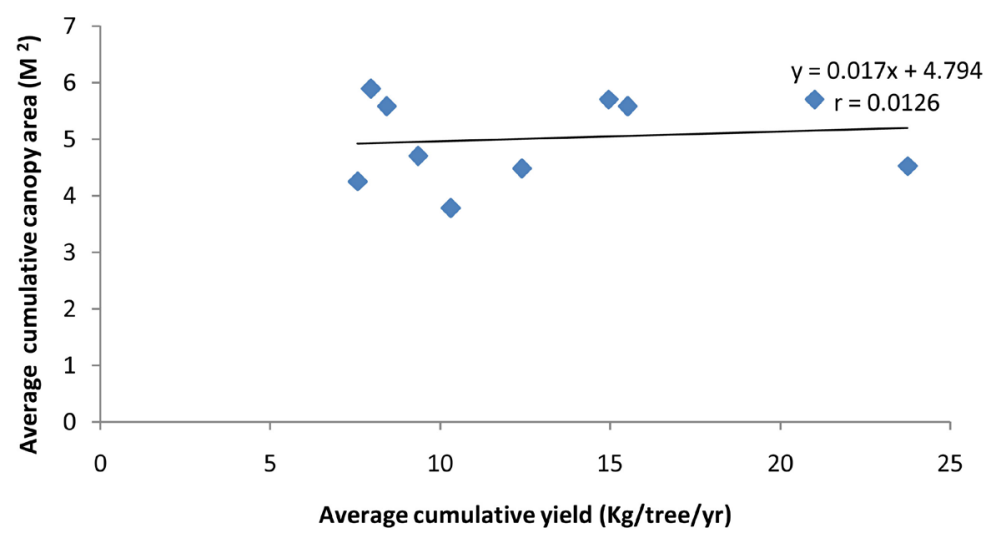

Figure 4. A graph of correlation between cumulative canopy area and average cumulative yield (2010 to 2013).

As breeders, strive for improved planting materials, it is worth considering the yield efficiency of the seemingly promising trees as the information will aid in the final selection of superior plants. Results from this study shows that yield efficiency increased steadily from 2010 to 2012 for all the clones. Despite the steady in- 
crement in the efficiencies, it could also be seen that most of the clones, including, W266 and W151 experienced a decline in the rate of yield efficiency in 2013. Such a decline might probably be due to canopy pruning carried out in early 2013 or possible translocation of assimilates for girth increment whilst assimilates for nut production might be hampered or reduced. In general, clones which recorded high efficiencies produced better yields compared to those with low efficiencies. In cocoa, Pang and Lockwood [26] demonstrated the application of yield efficiency in explaining heterosis and the performance of different groups of hybrids from their parental clones. Such information is useful in the identification of best performing plants as it is being applied in this study.

Aside the yield efficiency, nut weight analyzed indicated significant differences among the clones and this could be exploited further in breeding. Clone W227 recorded the highest nut weight of (8.6 g) whilst W151 recorded the least (4.9 g). A similar yield record was reported by Masawe [23] where the best performing hybrids (AC4 x AZA17) in terms of nut weight produced $8.33 \mathrm{~g} /$ nut six years after planting whilst the worst performing hybrids (NTP88-73 x CP1001) recorded $2.35 \mathrm{~g} /$ nut in a hybrid evaluation trial in south eastern Tanzania. The average nut weight in the present study was generally low, but was comparable to results reported elsewhere.

It is often seen that nuts with lower weight are likely to produce lower kernel weight, thus, raising the kernel export grade value since a lot more kernel would be required to yield 1 pound $(1 \mathrm{Lb})$ weight. According to the current data available, most of the clones which were significantly not different are likely to produce similar value for the kernel export grade.

High kernel export grade is directly associated with high percentage out turn, therefore, clones which recorded high values for kernel export grade are likely to produce high percentage out turn. According to data analyzed in this study, there exist significant differences in the percentage out turn of the various clones. This useful variation could be exploited in the selection of potential parent for the development of improved hybrids. Clone W278 which recorded $37.1 \%$ out turn seem outstanding when compared to the percentage out turn of $33 \%$ recorded by some leading hybrids developed in Tanzania [23]. Interestingly, a high percentage of the clones displayed appreciable out turn percentage

In an attempt to identify clones which combine high yields with moderate canopy area to encourage low density planting, canopy area was estimated and the results indicated significant differences between the canopy area of the clones. W227 which produced heavy nuts among the clones again recoded the largest canopy area whilst W273 recorded the least. Though clones such as W266 produced a relatively small canopy area, it recorded higher yields when compared to clones that produced large canopies. This observation confirmed a statistical analysis in this study which indicated that, there is no significant correlation between yield and canopy area. Higher yield might probably be more associated with canopy shape and genetics rather than canopy area.

\section{Conclusion}

We conclude here that, potential promising clones (W266 and W273) which produce high yields of four to five folds above the present average yields recorded by unselected trees within Northern Ghana have been identified. Furthermore, the out turn percentage demonstrated by majority of the clones is within the acceptable international standards. Nonetheless, the study did not find clones which combined high yields with high out turn percentage, clones with large nut weight and high yield efficiency at the same time. It is suggested that further studies should be undertaken on hybridization among the best different clones in other to transfer all the relevant traits into a single hybrid.

\section{Acknowledgements}

We wish to thank Mr. Gabriel Bohen of the Agronomy Division of CRIG and Mr. Akyea of the Ministry of food and agriculture, Wenchi for their Technical assistance. We also want to thank all the Technical staff of the Bole Substation, CRIG for their support and assistance especially Messrs Victor Agne, Fred Dzapala and Bismark Owusu-Ansah. This paper is published with permission of the Executive Director of Cocoa Research Institute of Ghana (CRIG) as manuscript number CRIG/011/2014/033/005.

\section{References}

[1] Nakasone, H.Y. and Paul, R.E. (1998) Tropical Fruits. CAB International, Oxon, 443.

[2] Aliyu, O.M. (2005) Application of Tissue Culture to Cashew (Anacardium occidentale L.) Breeding: An Appraisal. 
African Journal of Biotechnology, 4, 1485-1489.

[3] Ghana Shippers Council (GSC) (2009) Cashew Exports in Ghana.

[4] Topper, C.P., Caligari, P.D.S., Camara, M., Diaora S., Djaha, A., Coulibay F., Asante, A.K., Boamah, A., Ayodele, E.A. and Adebola, P.O. (2001) West African Regional Cashew Survey Report (Guinea, Guinea Bissau, Cote D’Ivore, Ghana and Nigeria). Sustainable Tree Crop Programme (STCP) and Biohybrids Agrisystem Ltd., UK, 110.

[5] Dwomoh, E.A., Afun, J.V.K. and Ackonor, J.B. (2008) Survey of Insect Species Associated with Cashew (Ancardium occidentalli Linn) and Their Distribution in Ghana. African Journal of Agricultural Research, 3, 205-214.

[6] CDP (2000) Cashew Development Project-Ghana. Appraisal Report GHA/PAAA/2000/01, 2000.

[7] Martin, P.J., Kasuga, L.J. and Bashiru, R.A. (1998) Cashew Farming Upgrading: Agronomic Options for Cashew Production by Smallholder Farmers in Tanzania. Experimental Agriculture, 34, 137-152. http://dx.doi.org/10.1017/S0014479798002014

[8] Aliyu, O.M. (2004) Characterization and Compatibility Studies in Cashew (Anacardium occidentale L.). Ph.D. Thesis, University of Ilorin Nigeria, Ilorin, 268.

[9] Opoku-Ameyaw, K., Amoah, F.M., Oppong, F.K. and Agene, V. (2007) Determination of Optimum Age for Transplanting Cashew (Anacardium occidentale) Seedlings in Northern Ghana. African Journal of Agricultural Research, 2, 296-299.

[10] Dadzie, M.A, Adu Gyamfi, P.K., Opoku-Ameyaw, K., Yeboah, J. and Dwumoh, E.A. (2012) Cashew Germplasm Collection, Conservation, Characterization and Utilization. CRIG Progress Report 2011-2012 and Work Plan 20122013, 331-334.

[11] Osei-Amaning, E. (1996) Managing of Vitellaraia paradoxa in Ghana. Ph.D. Thesis. University of Wales, Bangor, 203.

[12] FAO-UNESCO (1977) Soil Maps of the World: 1:50,000,000 Africa 6. UNESCO, Paris, 299.

[13] Masawe, P.A.L. (1994) Aspect of Breeding and Selecting Improved Cashew Genotypes (Anacardium occidentale L.). Ph. D. Thesis, University of Reading, UK.

[14] Azevedo, D.M.P., Crisóstomo, J.R., Almeida, F.C.G. and Rossetti, A.G. (1998) Estimates of Genetic Correlations and Correlated Responses to Selection in Cashew (Anacardium occidentale L.). Genetics and Molecular Biology (Online) 21. http://dx.doi.org/10.1590/S1415-47571998000300019

[15] Aliyu, O.M. (2006). Phenotypic Correlation and Path Coefficient Analysis in Cashew (Anacardium occidentale L.). Silvae Genetica, 55, 19-25.

[16] Masawe, P.A.L., Nfune, S. and Mbunda, Z. (2005) Performance of Cashew Hybrids Developed from Partial Dialed Crossing between Selected Clones in Tanzania. Tanzania Agricultural Research \& Training Newsletter, 20, 1-4.

[17] Eijnatten, C.L.M. and Abubaker, A.S. (1983) New Cultivation Techniques for Cashew (Anacardium occidentale L.). Netherlands Journal of Agricultural Sciences, 31, 13-25.

[18] Nair, R.B. and Prabhakaran, P.V. (1983) Optimum Size and Shape of Plots in Field Experiments with Cashew. Agricultural Research Journal of Kerala, 21, 27-34.

[19] Neto, V. (1992) Yield Variability of Cashew Trees in East Africa. PhD Thesis, University of Reading, UK.

[20] Mead, R. and Martin, A. (1992) Draft Report on Farmer Participation Research, On-Farm Research and Cashew Research. Naliendele Agricultural Research Institute, Mtwara, Tanzania.

[21] Cashew Week, 2006 (A product CommodityIndia.com). Vietnam Cashew Industry-Special Coverage, 5-6.

[22] Foltan, H. and Lüdders, P. (1995) Flowering, Fruit Set and Genotype Compatibility in Cashew. Angewandte Botanik, 69, 215-220.

[23] Masawe, P.A.L., Cundall, E.P. and Caligari, P.D.S. (1998) Performance in South-Eastern Tanzania of Local Cashew Germplasm and Selected Clones. Proceeding of the International Cashew and Coconut Conference, 17-21 February 1997, Dar es Salam, Tanzania. BioHybrids International Ltd., Reading, UK, 146-150.

[24] Samal, S., Rout, G.R. and Lenka, P.C. (2003) Analysis of Genetic Relationship between Populations of Cashew (Anacardium occidentale L) by Using Morphological Characterization and RAPD Markers. Plant Soil Environ, 49, 176182.

[25] Chaikiattiyos, S. (1985) Integrated Production Practices of Cashew in Thailand. Acta Horticulture (ISHS), 153.

[26] Thau-Yin, P.J. and Lockwood, G. (2008) A Re-Interpretation of Hybrid Vigour in Cocoa. Experimental Agriculture, 44, 329-338. 